\title{
Design and Performance Analysis of DSS (Dual Sink Based Scheme) Protocol for WBASNs
}

\author{
Abdul Ahad ${ }^{*}$, Saud Al Faisal2 ${ }^{*}$, Farzand Ali ${ }^{3}$, Bahlool Jan ${ }^{4}$, Niamat Ullah ${ }^{5}$ \\ ${ }^{1}$ Department of Computer Science, Virtual University of Lahore, Lahore, Pakistan \\ ${ }^{2}$ Department of Electronics Engineering, Comsats University, Islamabad, Pakistan \\ ${ }^{3}$ Department of Computer Science, Preston University, Islamabad, Pakistan \\ ${ }^{4}$ Department of Computer Science, University of Swat, Swat, Pakistan \\ ${ }^{5}$ Department of Computer Science, Abdul Wali Khan University, Mardan, Pakistan \\ Email: *ahad9388@gmail.com
}

How to cite this paper: Ahad, A., Al Faisal, S., Ali, F., Jan, B. and Ullah, N. (2017) Design and Performance Analysis of DSS (Dual Sink Based Scheme) Protocol for WBASNs. Advances in Remote Sensing, 6, 245-259.

https://doi.org/10.4236/ars.2017.64018

Received: October 12, 2017

Accepted: November 20, 2017

Published: November 23, 2017

Copyright $\odot 2017$ by authors and Scientific Research Publishing Inc. This work is licensed under the Creative Commons Attribution International License (CC BY 4.0).

http://creativecommons.org/licenses/by/4.0/

(c) (i) Open Access

\begin{abstract}
After a large improvement in health care services, Wireless Body Area Sensor Network (WBASN) is used in different fields where health care monitoring can be done continuously and from a distance. Many selected protocols are given in literature work which can improve the performance of WBASN by focusing on delay, routing and energy efficiency. In our research, we will focus on improving throughput, network life time, and decrease end-to-delay. In given research, the two sink nodes utilized and AnyCasting concept will be used. Dual Sinks based Scheme (DSS) for WBASN will be compared with existing DARE, SIMPLE, LAEEBA and M-ATTEMPT protocols. DSS performance found more efficient than DARE, SIMPLE, LAEEBA and M-ATTEMPT respectively in throughput. From results, DSS network life time is greater than DARE, SIMPLE, LAEEBA and M-ATTEMPT with minimum delay. In DSS, energy parameter is in tradeoff with the improved parameters, because of a computation of RSSI which do more process and utilize more energy.
\end{abstract}

\section{Keywords}

WBASNs, Network Life Time, End-to-End Delay, Throughput, Energy Consumption, AnyCasting, RSSI

\section{Introduction}

As we know that Computer Science is growing very quickly in every field to operate huge data and maintain top level of linking. At the current period, small scales of networks are also advanced which supports top level of mobility and accessibility [1] [2]. In Wireless Sensor Networks (WSNs), the Wireless Body 
Area Sensor Networks (WBASNs) is new field, started developing since 1995 [3]. The main purpose of this network is to create a communication link with human body. Before it was just developed for the health-care services but now it can also be used in many fields where distant health-care monitoring is necessary such as astronauts in space, motion detection of animals, players in sports, environmental conditions, security etc. [4] [5].

WBASNs is combination of small size sensors, these sensors have smallest amount of energy source and processing capability. These small size sensors can be wearable on body or may also be set inside the body, depending upon the application [2].

The sensors set inside body have low data rate and power consumptions as compared to wearable devices [6] [7]. In medical field, different types of sensors are attached to the patient body which is residing at home or hospital. The main purpose of these sensors is to calculate and detect different types of biological parameters of patient body such as temperature, blood-rate, glucose-rate, blood pressure, Electrocardiogram (ECG) and heart beat etc. [8]. The produced signals are collected by personal device, e.g. Personal Digital Assistance (PDA), its main function is to act like relay node and send the data to the doctor or to some internet using applications with the help of sink node. These sinks work as router between WBASNs and hospitals [9].

In WBASNs, sensors nodes have limited energy source and these sensor nodes are battery driven [7]. So, it is compulsory to transmit data from sensors nodes to sink using minimum energy. Another challenge in this network is to recharge the batteries of sensor nodes after discharge, therefore energy efficient protocol is required which diminish this issue. In [4] some challenges are found by researchers which are faced by WBASNs as following:

- High level of attenuation as compared to other WSNs applications

- Trade-off between communication and processing

- Bandwidth and power consumption

- Storage and energy harvesting

Generally, the sink in WBASNs collects data from battery-powered sensors nodes and transmits the data to the sink node using unicast transmission. In this transmission, each sensor node has only one destination, which is single sink. Each node senses the data and transmits to this single sink node. Here issue can arise while transmitting data through unicasting and using a single sink. This will be discussed in later section. We have another way to used two sinks which is well approach in WSNs; in this approach, environmental information is sensed by sensors and transmits to the available sink node in AnyCast manner [10]. Anycasting approach is best working technology in WSNs and no one use this technology in WBASNs.

In current period of time sensor network is popular area for research. Wireless sensor networks are used in different fields such as Military, Health, and sports etc [11] but WSNs is also some disadvantages such as bandwidth and security etc [12] [13]. Many papers have been published on Energy Efficiency, 
Quality of Service (QoS), Security and Bandwidth [14] [15]. The topology used for nodes in a body and the transmission of data between sink and sensors will be focusing point. Therefore, in this research we will discuss these issues by considering the transmission technique.

Organization of paper as follow: In section 2 information will be provided about existing works. In section 3 motivation behind this research will be discussed. In section 4 DSS model, phases, simulations and results will be presented. Section 5 will conclude the paper.

\section{Related Work}

Different protocols are presented by different researchers in their papers to improve the performance and reliable communication. Few of them are discussed below.

In paper [1] for Wireless Body Area Networks (InCo-CEStat) the researchers proposed incremental relay-based CoCEStat protocol. For cooperation purpose researchers uses two relay nodes which transmit the critical data quickly in emergency cases in WBASNs. These relay nodes collect the data from sensors and send it to the destination single sink node in three steps with duplicate copy which can made packet drop chances decrease.

In paper [2] DARE protocol is proposed by the researchers. DARE protocol is used to supervise eight patients in a ward, each comprises of seven sensors to supervise the patient body parameters. For this situation, the five topological scenarios are proposed in which more than one sink node is set in different locations in the ward.

In paper [3] research proposed a protocol having name SIMPLE. In SIMPLE protocol, researchers used single sink node and eight sensors in human body. In short span of time nodes lose energy therefore, mathematical formula is suggested to balance network life time and energy level of the network.

In [5], researchers present THE-FAME (Threshold based Energy-efficient Fatigue Measurement) protocol to find out fatigues of a player in Soccer game. Each player is surrounded with sensor nodes to sense fatigues parameter of a player. On different sides of game multiple sink nodes are attached. These small sizes of sensor send data directly when threshold level is reached.

In paper [6], researches present software and hardware architecture, data transmission and error detection for emergency and normal data. Researchers used cluster head $(\mathrm{CH})$ to collect the parametric data. In paper [7], LABEEBA protocol is proposed by researchers for Wireless Body Area Networks. In this plan researcher used both multi-hop communication and direct communication by focusing the path loss. To reduce energy consumption a cost function is calculated.

In paper [8] researchers present an Effect of Packet Inter-arrival Time on the Energy Consumption of Beacon Enable MAC Protocol for WBASNS. In this paper, all the focus is on Media Access Control (MAC) to minimize the energy consumption. In this protocol two types of nodes are used; Reduced Functional 
Devices (RFD) and Fully Functional Devices (FFD). Reduced Functional Devices (RFD) work as simple node while Fully Functional Devices (FFD) can be coordinator node or simple node.

In paper [9], M-ATTEMPT protocol is presented. M-ATTEMPT protocol is threshold based routing protocol which finds out the spot link between established links. In this scheme researchers set the sensors in declining order of their data rate with respect to the sink. Both of two multi hope and single hope communication is used for normal and emergency data.

In paper [16], researchers presented a routing protocol which focuses mainly on the accessibility of patient's data either online or offline to the health care agents. In this model, sensors are positioned on different parts of patient clothes (on body). These sensors collect data from accumulator and send it to the medical server through Wi-Fi. In paper [17], researchers get four attributes in accounts. These four attributes are residual energy, node criticality, distance covered and hop-count. Routing occurs in two steps i.e., operational phase and setup phase.

In paper [18], researchers presented a cost based routing protocol for Wireless Body Area Networks. Cost function and energy efficiency is focused in this paper to considering the reliability path on the basis of critical factor. In paper [19], researchers used two protocols Energy efficient self-adaptive route E-DSR and Source Routing (DSR) with the help of tree topology to decrease the network lifecycle and energy consumption.

In paper [20], researches proposed a protocol which avoid single point of failure and maximize the throughput in WBASNs. This protocol used Cooperative Network Coding (CNC) in many to many as multiple input multiple output (MIMO). In paper [21] researcher presented a strong and fast routing protocol focused on design topology. It is because of heterogeneity of sensor nodes and their energy consumption.

In paper [22], researchers present a mathematical technique which uses cross layer optimization and network topology in WBSNs. In this technique, they used multilevel primal and dual decomposition methods to solve the non-convex mixed integer optimization problem. In paper [23], researchers design network architecture which uses cloud and WBASNs for data sharing. In this architecture data is sharing in four different layers. This process is done with the help on TCP/IP and Zigbee.

\section{Motivation}

According to study and survey, most of the researchers [1] [3] [7] [24] [25] used single sink node to collect data and send it to destination. In this situation, some problems may be occurring. On which researcher did not focus. These problems are following:

- If single sink node stops working for some time or die, then the entire network will fail.

- All the data is send to this single sink node which make burden on this single 
sink node to collect data and fast delivery. In over burden problem make delay between packets, especially in emergency cases in which fast delivery needed. Performance factor improved when more packets are sending in less time with error free to the medical caretaker. The overburden problem minimizes the delivery ratio.

In paper [18], researchers set the sink at wrist when arm of a body moves forth and back it make disconnection with the previous established link due to NLoS. To keep in mind above discussed problem we proposed a scheme DSS for WBASNs. In which performance is improving the take care of network life time, delivery ration and end-to-end delay.

In paper [21], the researcher proposed a scheme to make fast and strong design for WBASNs. In this strategy researchers used more number of relay nodes which is almost equal to the normal nodes, leads to decrease the delivery ratio and increase the network cost, on which the researcher did not focused. To set the sink on exact position it is necessary to considering NLoS and LoS. Misplacement of sink will lead to disconnection of sink from sensors when the parts of a body move.

\section{DSS Proposed Protocol}

In this section, we will propose our DSS routing protocol for WBASNs with AnyCasting technique to maximize the performance by using two sinks.

\subsection{System Model}

In DSS proposed model, we set eight sensors with two sinks having name S1 and S2. In the case of moving parts of a body S1 will be set on right lumbar while S2 will be set on left lumber to consider NLoS communication. In both cases of moving forth and back of arm in LoS communication with lumber, therefore it is best placed for sinks we choose. In this topology, the 1st and 4th node send data directly to S1 and S2 in order to consider the NLoS issue (as discussed above). The other nodes which are indirect range to either sinks, send data in direct communication and another send through multi-hop communication to select the forwarder node. Our DSS protocol topology is given in Figure 1.

\subsection{Initialization Phase}

In this step, "hello" is broadcast from two sinks to all sensor nodes which contain sink ID and location. After receiving this message, the sensor nodes save location and sink ID in their routing table. These sensor nodes also broadcast different packets which contain the energy level of node, node ID and their location. In this manner, every sensor node is aware from his neighbor's sensor nodes.

\subsection{Next-Hop Selection Phase}

DSS protocol computes the forwarder node on the base of threshold Residual Energy (RE). DSS protocol fix threshold value of Residual Energy (RE) is equal to $0.1 \mathrm{~J}$. 


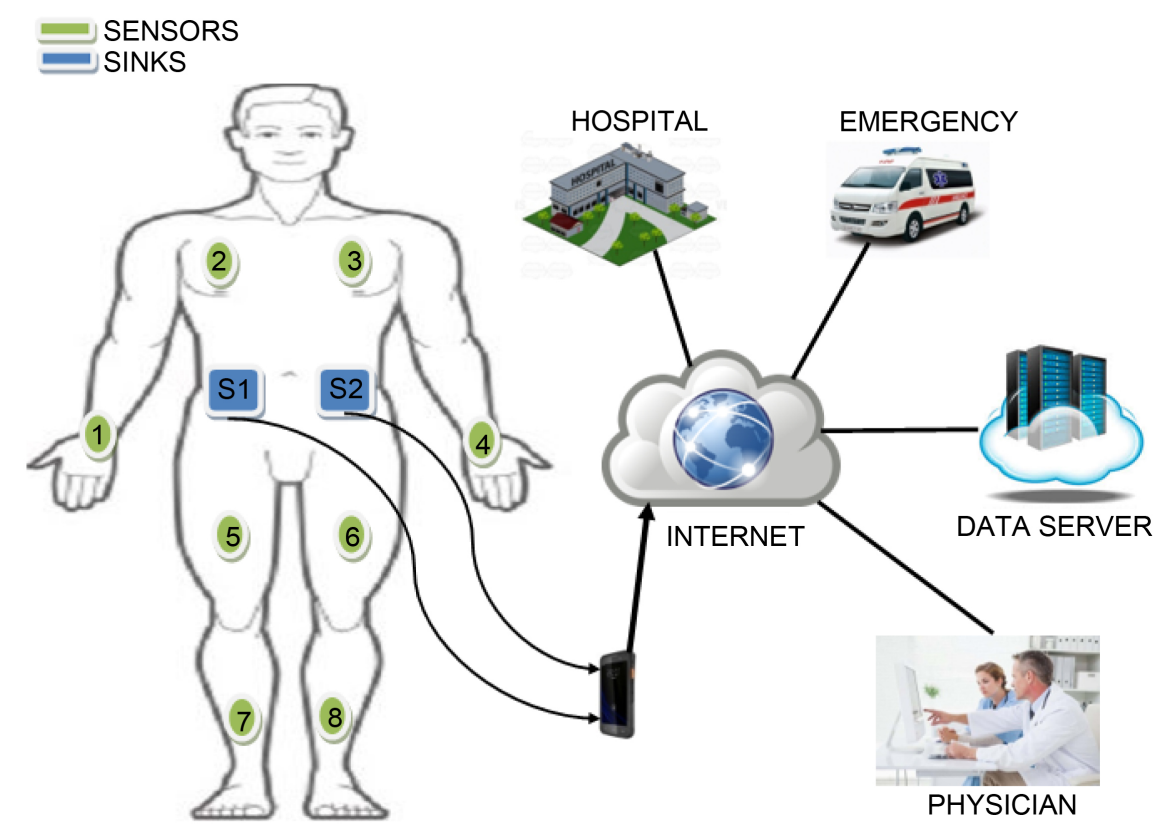

Figure 1. Schematic diagram of DSS protocol.

$\mathrm{RE} \geq$ threshold where threshold is equal to $0.1 \mathrm{~J}$

Here, if more than one node has greater Residual Energy (RE) than threshold, than Received Signal Strength Identification (RSSI) will select forwarder node [26]. Received Signal Strength Identification (RSSI) explains the relationship between received power, the transmitted power of a signal and the distance between them.DSS follow Received Signal Strength Identification (RSSI) model of paper [2] the Equation (2) is mentioned below.

$$
\operatorname{Pr}=\operatorname{Pt}\left(\frac{1}{d}\right)^{n}
$$

In Equation (2) Pr shows wireless signal received power. Pt is a power transmitted by the wireless signal and $d$ denoted the distance between receiving and sending node. Transmission factor between receiving and sending node is denoted by $n$, the value of $\mathrm{n}$ depends on propagation environment. According of equation, that node is selected for forwarder node which has maximum $\operatorname{Pr}$ value.

\subsection{Routing and Energy Consumption Phase}

Another benefit of using two sinks is that most of the nodes will be comes in direct range. In direct communication delivery of packets are very quick and without any delay. According to the DSS protocol, 1st and 4th node send data to S1 and S2 sink directly to consider arm movement. Those nodes which are in the range of S1 or S2 sink will send data directly to them, while other nodes will AnyCast to S1 or S2 through relay node in multi hop communication. In Figure 2 communication flow of DSS protocol is mentioned.

Energy consumption in multi-hop (Em) communication is mentioned below [5]: 


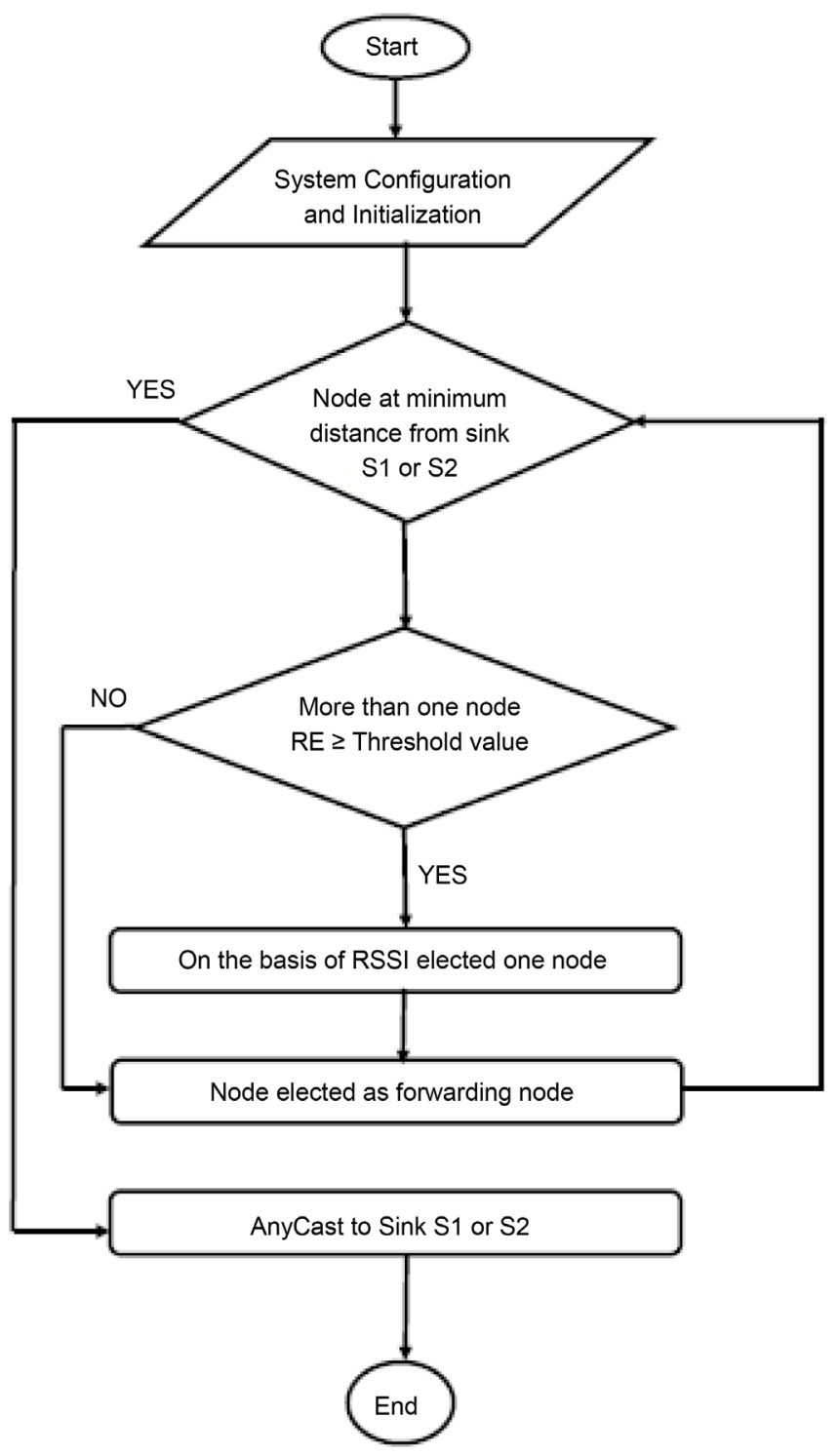

Figure 2. Flow chart for DSS protocol.

$$
\begin{gathered}
\text { ERt-m }(k, d)=n \times(\text { ERcr }+ \text { ERamp }) \times k \times d 2 \\
\operatorname{ERr-m}(k)=(n-1) \times(\text { ERcr }+ \text { ERamp }) \times k \\
\text { ERtotal-m }=\text { ERt-m }+ \text { ERr-m }
\end{gathered}
$$

Energy consumption in direct (ED) communication is [5]:

$$
\begin{gathered}
\text { ERt-D }(k, d)=(\text { ERcr }+ \text { ERamp }) \times k \times d 2 \\
\text { ERtotal-D }=\text { ERt-D }
\end{gathered}
$$

Here ERt and ERr are the energies which are required for the transmission and receiving. $k$ in the equation represents size of bits while $d$ represent the distance between sinks and nodes. ERcr is the energy which is required to operate the transmitter and receiver electronic circuit. ERamp is the energy required to increase $k$ bits to the distance $d$. In the above given Equations (3) and (4), $n$ 
represent number of nodes which is required to reach the sinks while $d 2$ represent the loss energy during transmitting data. The energy parameters depend upon the use of hardware. Energy parameters which are used in DSS protocol is mentioned below in the Table 1 .

\subsection{Simulation Results and Discussions}

In this paper, we conducted a sequence of simulations to obtain our proposed protocol DSS performance. Then we compared our protocol with existing protocols having name DARE, SIMPLE, LAEEBA and M-ATTEMPT. All the five protocols are compared for the same key performance parameters which are following:

- Network Life Time

- End-to-End Delay

- Throughput

- Residual Energy

\subsubsection{Network Life Time}

It is the time of network operation till the first node of network dies. As from Figure 3, the performance of DSS protocol is better than DARE, SIMPLE, LAEEBA and M-ATTEMPT protocols. In Table 2, the numerical values of dead nodes are given for the five protocols which are starting from $600 \mathrm{~s}$ till $9000 \mathrm{~s}$. It can be observed from the Table 2, DARE protocol first node dies at $4800 \mathrm{~s}$, SIMPLE protocol first node dies at $4800 \mathrm{~s}$, LAEEBA protocol first node dies at $2400 \mathrm{~s}$, while M-ATTEMPT protocol first node dies at $3400 \mathrm{~s}$ and DSS protocol

Table 1. Simulation parameters.

\begin{tabular}{cc}
\hline Parameters & Values \\
\hline DC current (RX) & $18 \mathrm{Ma}$ \\
DC current (TX) & $10.5 \mathrm{Ma}$ \\
Minimum supply voltage & $1.9 \mathrm{~V}$ \\
ERr & $36.1 \mathrm{~nJ} / \mathrm{bit}$ \\
ERt & $16.7 \mathrm{~nJ} / \mathrm{bit}$ \\
ERamp & $1.97 \mathrm{~nJ} / \mathrm{bit}$ \\
Wavelength ( $\lambda$ ) & $0.135 \mathrm{~m}$ \\
Frequency (f) & $2.5 \mathrm{GHz}$ \\
Initial Energy (Eo) & $0.7 \mathrm{~J}$ \\
do & 0.15 \\
\hline
\end{tabular}

Table 2. Dead nodes after equal intervals.

\begin{tabular}{|c|c|c|c|c|c|c|c|c|c|c|c|c|c|c|c|}
\hline $\begin{array}{c}\text { Time } \\
\text { (In Seconds) }\end{array}$ & 600 & 1200 & 1800 & 2400 & 3000 & 3600 & 4200 & 4800 & 5400 & 6000 & 6600 & 7200 & 7800 & 8400 & 9000 \\
\hline DARE & 0 & 0 & 0 & 0 & 0 & 0 & 0 & 1 & 1 & 6 & 6 & 6 & 8 & 8 & 8 \\
\hline SIMPLE & 0 & 0 & 0 & 0 & 0 & 0 & 0 & 1 & 2 & 5 & 5 & 6 & 6 & 8 & 8 \\
\hline LAEEBA & 0 & 0 & 0 & 0 & 2 & 2 & 3 & 3 & 3 & 3 & 4 & 4 & 8 & 8 & 8 \\
\hline $\begin{array}{cc}\text { M-ATTE } \\
\text { MPT } \\
\text { MPT }\end{array}$ & 0 & 0 & 0 & 3 & 3 & 3 & 3 & 3 & 3 & 3 & 3 & 4 & 8 & 8 & 8 \\
\hline DSS & 0 & 0 & 0 & 0 & 0 & 0 & 0 & 0 & 0 & 0 & 0 & 1 & 6 & 6 & 6 \\
\hline
\end{tabular}




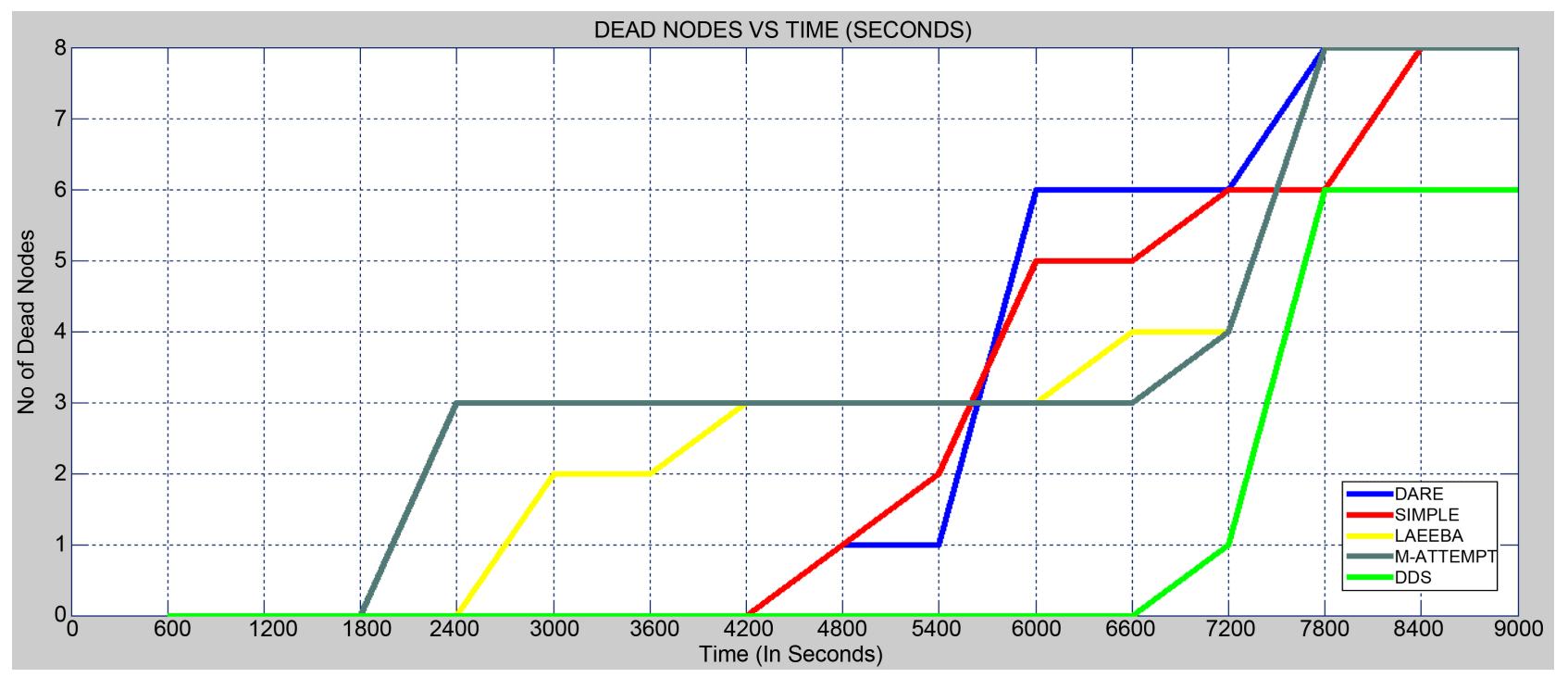

Figure 3. Network life time vs time (seconds).

first node dies at 7200 . The DSS performance increased because of more than one sink. The availability of two sinks help nodes to send the data to its nearest sink node. Another reason of the better performance is the setting of sinks at best location. The sensor nodes on wrist directly communicate with S1 and S2 without NLoS issue. All these factors increase the DSS performance up to 9000 times. All nodes of DARE, SIMPLE, LAEEBA and M-ATTEMPT dies at $7800 \mathrm{~s}$ while DSS last node still alive at $9000 \mathrm{~s}$.

\subsubsection{End-to-End Delay}

The word delay refers to time lag between source nodes and destination sinks. Decreasing delay in WBASNs is very important aspect. The medical officer evaluates the senses data therefore; it is important that the data received in time. It can be achieved if the data collected by the sinks in time. The performance of DSS is much better as compared to DARE, SIMPLE, LAEEBA and M-ATTEMPT protocols as shown in Figure 4. In Table 3, numerical value of average delay is mentioned, the Table 3, shows that DSS average is 181.50 , which is $26 \%$ better than DARE, 7\% better than SIMPLE, $4 \%$ better than LAEEBA and $25 \%$ better than M-ATTEMPT protocol. The obtained performance is because of the availability of AnyCasting between two sink nodes. In DSS, the sensor nodes can send their data in two ways. DARE, SIMPLE, LAEEBA and M-ATTEMPT protocol uses single sink which take more time in calculation to collect data from more sensor nodes. In DSS, the two sink makes the performance increase because every sink collect data from few sensors node. Another reason of better performance of DSS compared to DARE, SIMPLE, LAEEBA and M-ATTEMPT is that more sensors in DSS directly communicate either to S1 or S2 and the distance between sinks and sensors become lessen. It can observe from literature survey that in direct communication delay will decrease as compared to multi hop communication if the distance is lessened. 


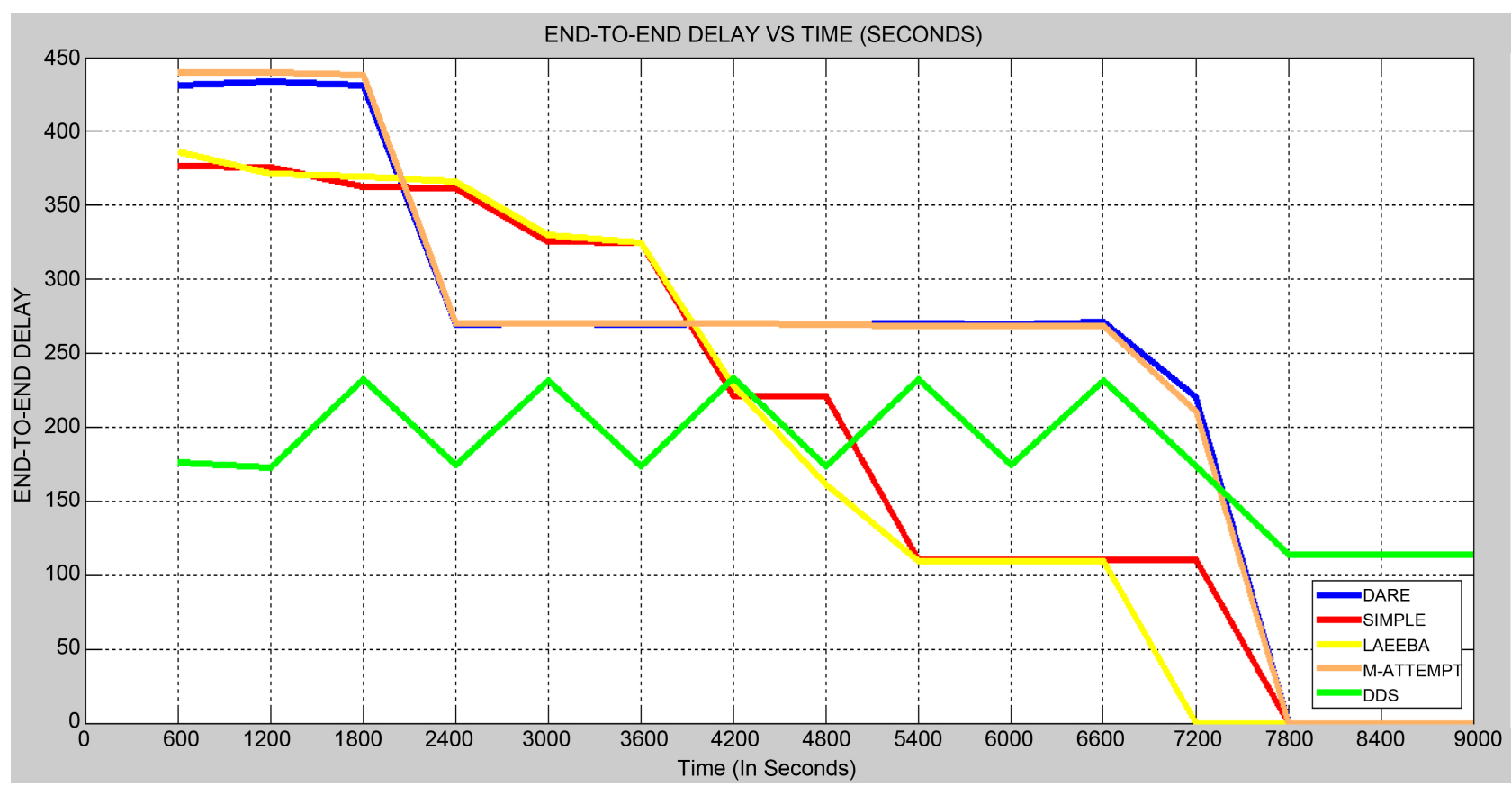

Figure 4. End-to-End delay (seconds) vs time (seconds).

Table 3. End-to-End delay after equal intervals.

\begin{tabular}{|c|c|c|c|c|c|c|c|c|c|c|c|c|c|c|c|c|}
\hline & $\begin{array}{l}\text { Time } \\
\text { (In Seconds) }\end{array}$ & 600 & 1200 & 1800 & 2400 & 3000 & 3600 & 4200 & 4800 & 5400 & 6000 & 6600 & 7200 & 7800 & 8400 & 9000 \\
\hline \multirow{5}{*}{ 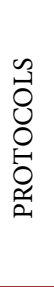 } & DARE & 431.2 & 433.6 & 431.1 & 269.1 & 270.2 & 269.7 & 270.4 & 269.3 & 270.6 & 269.3 & 270.9 & 220.4 & 0 & 0 & 0 \\
\hline & SIMPLE & 376.2 & 376.1 & 362.4 & 362.1 & 325.6 & 324.9 & 221.4 & 220.9 & 110.6 & 110.4 & 110.1 & 109.9 & 0 & 0 & 0 \\
\hline & LAEEBA & 386.1 & 371.2 & 369.4 & 365.7 & 329.9 & 325.1 & 227.8 & 160.9 & 109.3 & 109.3 & 109.3 & 0 & 0 & 0 & 0 \\
\hline & M-ATTEMPT & 440.2 & 439.6 & 438.1 & 270.5 & 270.4 & 270.1 & 269.9 & 269.6 & 268.8 & 268.2 & 268.1 & 210.9 & 0 & 0 & 0 \\
\hline & \multirow[t]{2}{*}{ DSS } & 176.6 & 172.4 & 232.6 & 174.1 & 231.9 & 173.6 & 233.4 & 173.9 & 232.1 & 174.7 & 231.4 & 173.6 & 114.1 & 114.1 & 114.1 \\
\hline & & & & & \multicolumn{2}{|c|}{ DARE } & \multicolumn{2}{|c|}{ SIMPLE } & \multicolumn{2}{|c|}{ LAEEBA } & \multicolumn{3}{|c|}{ M-ATTEMPT } & \multicolumn{3}{|c|}{ DSS } \\
\hline \multirow{2}{*}{\multicolumn{2}{|c|}{ PERFORMANCE }} & \multicolumn{3}{|c|}{ AVERAGE } & \multicolumn{2}{|c|}{245.05} & \multicolumn{2}{|c|}{181.50} & \multicolumn{2}{|c|}{190.93} & \multicolumn{3}{|c|}{245.62} & \multicolumn{3}{|c|}{181.50} \\
\hline & & \multicolumn{3}{|c|}{ PERCENTAGE } & \multicolumn{2}{|c|}{$100 \%$} & \multicolumn{2}{|c|}{$81.92 \%$} & \multicolumn{2}{|c|}{$77.93 \%$} & \multicolumn{3}{|c|}{$100.25 \%$} & \multicolumn{3}{|c|}{$74.08 \%$} \\
\hline
\end{tabular}

\subsubsection{Throughput}

Throughput is the delivery of packets successfully from sensors nodes to sinks in per unit time. Here unit is second which is started from $600 \mathrm{~s}$ to $9000 \mathrm{~s}$. The data in DSS is send through two links one is from sensors to forwarder node and second one is from forwarder node to sinks. The link between forwarder node and sink transmits more data from other links. So, in DSS strategy more sensors of network placed near to sinks, these sensors send data directly to sink, due to which throughput of network increase. Figure 5, shows the performance between five protocols. From results, it is obtained that DSS performance is better than other four protocols. According to the Table 4, DSS average value is 26,400 which shows DSS is $23 \%$ better than DARE, $11 \%$ better than SIMPLE, $49 \%$ better than LAEEBA and $48 \%$ better than M-ATTEMT. 


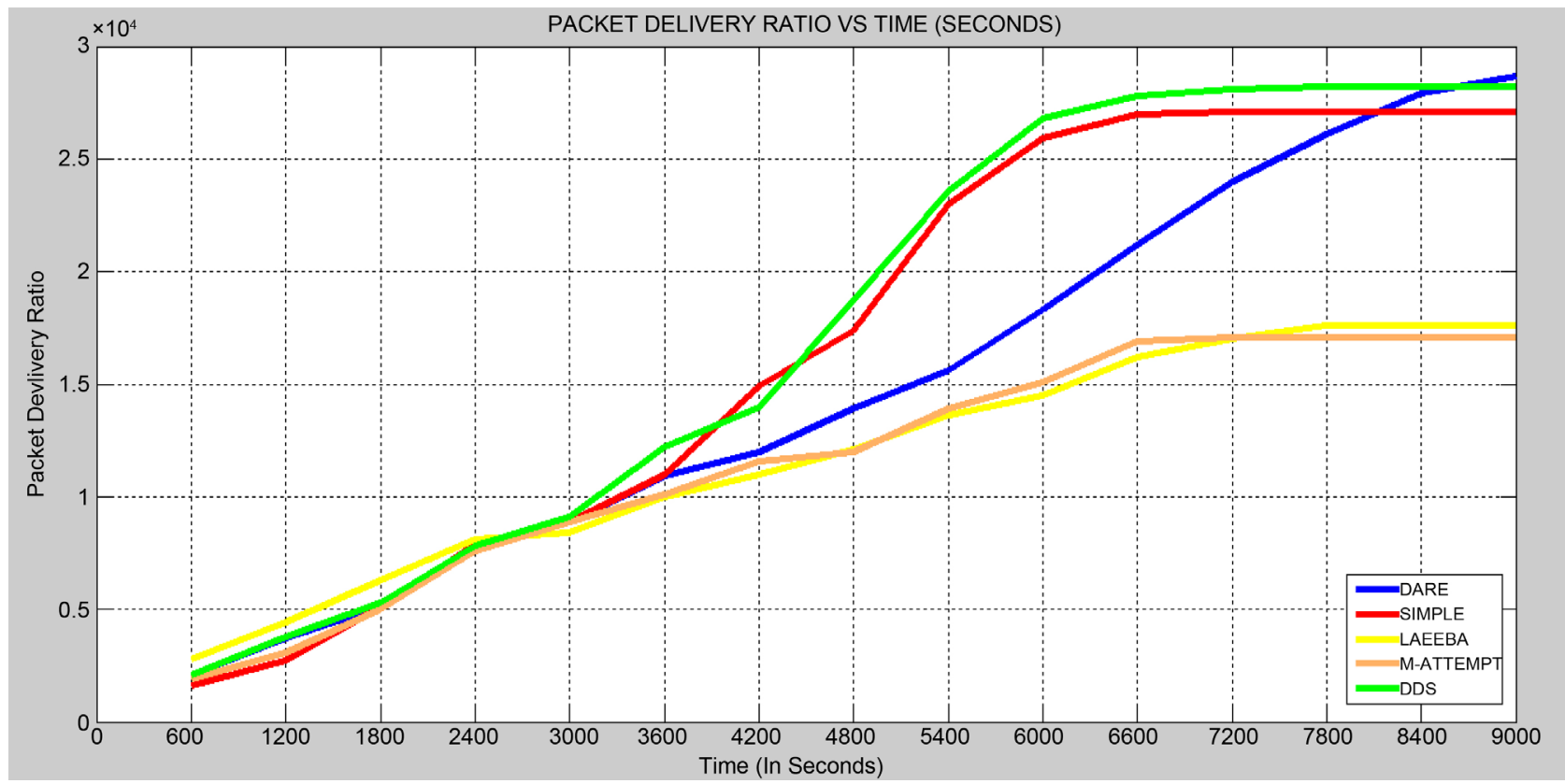

Figure 5. Throughput vs time (seconds).

Table 4. Packet delivery ratio after equal intervals.

\begin{tabular}{|c|c|c|c|c|c|c|c|c|c|c|c|c|c|c|c|c|}
\hline & $\begin{array}{c}\text { Time } \\
\text { (In Seconds) }\end{array}$ & 600 & 1200 & 1800 & 2400 & 3000 & 3600 & 4200 & 4800 & 5400 & 6000 & 6600 & 7200 & 7800 & 8400 & 9000 \\
\hline \multirow{6}{*}{ 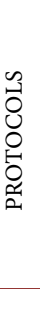 } & DARE & $0.21 e+04$ & $0.37 e+04$ & $0.51 \mathrm{e}+04$ & $0.77 \mathrm{e}+04$ & $0.89 \mathrm{e}+04$ & $1.09 \mathrm{e}+041$ & $1.20 \mathrm{e}+04$ & $1.39 \mathrm{e}+04$ & $1.56 \mathrm{e}+04$ & $1.83 \mathrm{e}+04$ & $42.12 \mathrm{e}+04$ & $2.40 \mathrm{e}+042$ & $2.61 \mathrm{e}+04$ & $2.79 \mathrm{e}+04$ & $42.87 \mathrm{e}+04$ \\
\hline & SIMPLE & $0.16 \mathrm{e}+04$ & $0.27 e+04$ & $0.51 e+04$ & $079 e+04$ & $0.89 e+04$ & $1.10 \mathrm{e}+04$ & $1.49 \mathrm{e}+04$ & $1.74 \mathrm{e}+042$ & $2.30 \mathrm{e}+04$ & $2.59 \mathrm{e}+04$ & $42.70 \mathrm{e}+04$ & $2.71 \mathrm{e}+042$ & $2.71 \mathrm{e}+04$ & $2.71 \mathrm{e}+04$ & $42.71 \mathrm{e}+04$ \\
\hline & LAEEBA & $0.28 \mathrm{e}+04$ & $0.44 e+04$ & $0.63 e+04$ & $0.81 \mathrm{e}+04$ & $0.84 \mathrm{e}+04$ & $1.00 \mathrm{e}+041$ & $1.10 \mathrm{e}+04$ & $1.21 \mathrm{e}+041$ & $1.36 \mathrm{e}+04$ & $1.45 \mathrm{e}+04$ & $41.62 \mathrm{e}+04$ & $1.70 \mathrm{e}+041$ & $1.76 \mathrm{e}+04$ & $1.76 e+04$ & $41.76 \mathrm{e}+04$ \\
\hline & M-ATTEMPT & $0.19 e+04$ & $0.31 e+04$ & $0.50 \mathrm{e}+04$ & $0.76 \mathrm{e}+04$ & $0.89 \mathrm{e}+04$ & $1.01 \mathrm{e}+041$ & $1.16 \mathrm{e}+04$ & $1.20 \mathrm{e}+04$ & $1.39 \mathrm{e}+04$ & $1.51 \mathrm{e}+04$ & $41.69 \mathrm{e}+04$ & $1.71 \mathrm{e}+041$ & $1.71 \mathrm{e}+04$ & $1.71 \mathrm{e}+04$ & $41.71 \mathrm{e}+04$ \\
\hline & \multirow[t]{2}{*}{ DSS } & $0.21 \mathrm{e}+04$ & $0.38 \mathrm{e}+04$ & $0.53 \mathrm{e}+04$ & $0.78 \mathrm{e}+04$ & $0.91 \mathrm{e}+04$ & $1.22 \mathrm{e}+041$ & $1.40 \mathrm{e}+04$ & $1.87 \mathrm{e}+042$ & $2.36 \mathrm{e}+04$ & $2.68 \mathrm{e}+04$ & $42.78 \mathrm{e}+04$ & $2.81 \mathrm{e}+042$ & $2.82 \mathrm{e}+04$ & $2.82 \mathrm{e}+04$ & $42.82 \mathrm{e}+04$ \\
\hline & & & & & \multicolumn{2}{|c|}{ DARE } & \multicolumn{2}{|c|}{ SIMPLE } & \multicolumn{3}{|c|}{ LAEEBA } & \multicolumn{2}{|c|}{ M-ATTEMPT } & \multicolumn{3}{|c|}{ DSS } \\
\hline \multirow{2}{*}{\multicolumn{2}{|c|}{ IMPROVEMENT }} & \multicolumn{3}{|c|}{ AVERAGE } & \multicolumn{2}{|c|}{22,600} & \multicolumn{2}{|c|}{24,600} & \multicolumn{3}{|c|}{17,700} & \multicolumn{2}{|c|}{17,800} & \multicolumn{3}{|c|}{26,400} \\
\hline & & \multicolumn{3}{|c|}{ PERCENTAGE } & \multicolumn{2}{|c|}{$127.68 \%$} & \multicolumn{2}{|c|}{$138.98 \%$} & \multicolumn{3}{|c|}{$100 \%$} & \multicolumn{2}{|c|}{$100.56 \%$} & \multicolumn{3}{|c|}{$149.15 \%$} \\
\hline
\end{tabular}

\subsubsection{Residual Energy}

To obtain clear result, we kept $0.7 \mathrm{~J}$ initial energy for all five protocols. The Table 5 and Figure 6 show that DSS energy level is greater than SIMPLE, LAEEBA and M-ATTEMPT but not good than DARE. The energy parameter in DSS comes in tradeoff with delay, throughput and network life time. Our aim in DSS was to improve the parameters mentioned above which have been proved by showing efficient results. However, DSS protocol shows improved performance than SIMPLE, LAEEBA and M-ATTEMPT protocols.

DARE protocol energy performance improved form DSS just because that DARE only focused on energy parameter in WBASNs. In DSS we focused on throughput, end-to-end delay and network life time parameters to improve. Another cause of reduction in energy is the using of RSSI in DSS protocol. In our proposed DSS protocol, extra calculation is required to find out forwarder 


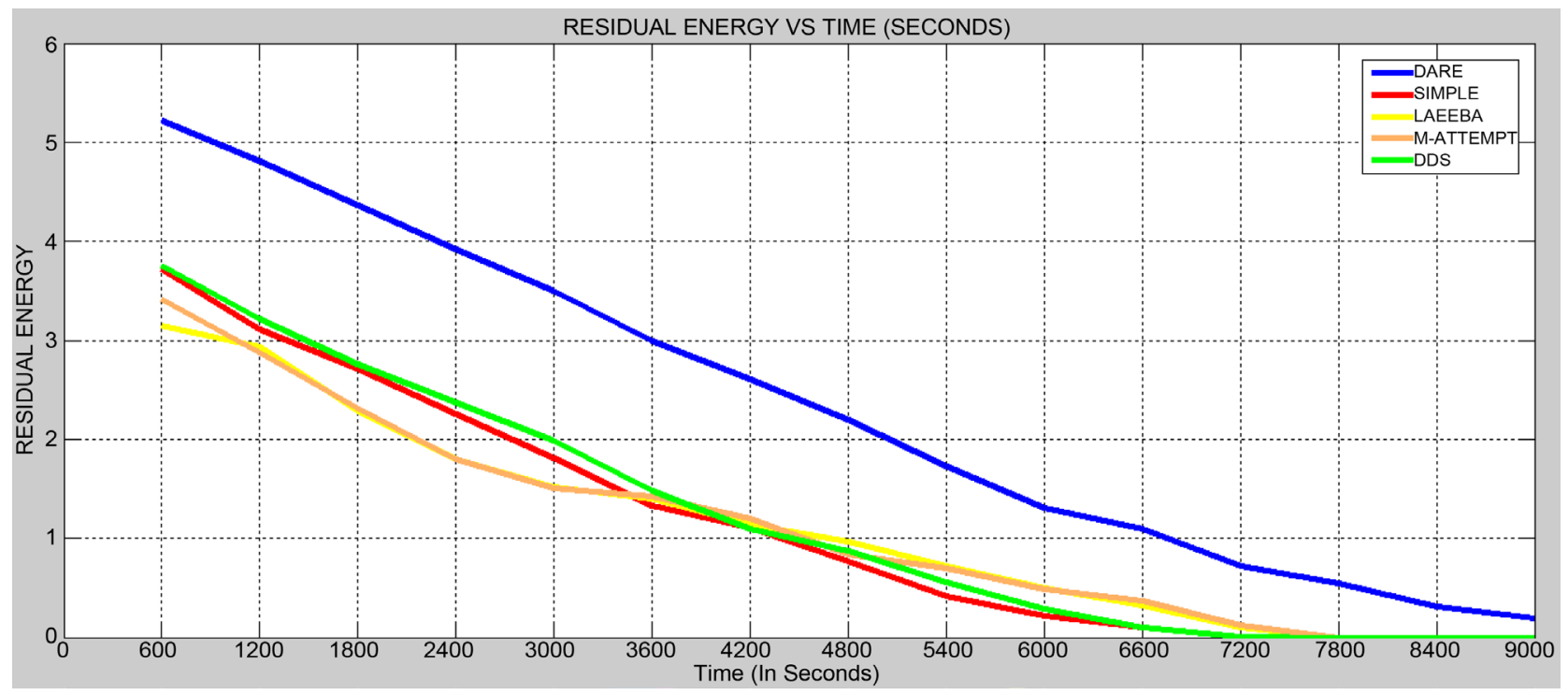

Figure 6. Residual energy vs time (seconds).

Table 5. Residual energy after equal intervals.

\begin{tabular}{|c|c|c|c|c|c|c|c|c|c|c|c|c|c|c|c|c|}
\hline & $\begin{array}{c}\text { Time } \\
\text { (In Seconds) }\end{array}$ & 600 & 1200 & 1800 & 2400 & 3000 & 3600 & 4200 & 4800 & 5400 & 6000 & 6600 & 7200 & 7800 & 8400 & 9000 \\
\hline \multirow{6}{*}{ 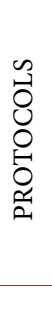 } & DARE & 5.216 & 4.813 & 4.369 & 3.916 & 3.496 & 2.996 & 2.610 & 2.199 & 1.726 & 1.311 & 1.096 & 0.718 & 0.541 & 0.316 & 0.194 \\
\hline & SIMPLE & 3.719 & 3.106 & 2.709 & 2.261 & 1.816 & 1.327 & 1.109 & 0.771 & 0.418 & 0.211 & 0.101 & 0.008 & 0 & 0 & 0 \\
\hline & LAEEBA & 3.146 & 2.936 & 2.296 & 1.799 & 1.516 & 1.399 & 1.141 & 0.961 & 0.716 & 0.501 & 0.321 & 0.101 & 0 & 0 & 0 \\
\hline & M-ATTEMPT & 3.416 & 2.876 & 2.319 & 1.796 & 1.501 & 1.421 & 1.196 & 0.836 & 0.699 & 0.491 & 0.365 & 0.119 & 0 & 0 & 0 \\
\hline & \multirow[t]{2}{*}{ DSS } & 3.761 & 3.211 & 2.761 & 2.369 & 1.992 & 1.486 & 1.101 & 0.869 & 0.561 & 0.291 & 0.096 & 0.009 & 0 & 0 & 0 \\
\hline & & & & & \multicolumn{2}{|c|}{ DARE } & \multicolumn{2}{|c|}{ SIMPLE } & \multicolumn{2}{|c|}{ LAEEBA } & \multicolumn{3}{|c|}{ M-ATTEMPT } & \multicolumn{3}{|c|}{ DSS } \\
\hline \multirow{2}{*}{\multicolumn{2}{|c|}{ IMPROVEMENT }} & \multicolumn{3}{|c|}{ AVERAGE } & \multicolumn{2}{|c|}{2.3678} & \multicolumn{2}{|c|}{1.1704} & \multicolumn{2}{|c|}{1.1222} & \multicolumn{3}{|c|}{1.189} & \multicolumn{3}{|c|}{1.2338} \\
\hline & & \multicolumn{3}{|c|}{ PERCENTAGE } & \multicolumn{2}{|c|}{$210.99 \%$} & \multicolumn{2}{|c|}{$104.29 \%$} & \multicolumn{2}{|c|}{$100 \%$} & \multicolumn{3}{|c|}{$105.95 \%$} & \multicolumn{3}{|c|}{$109.94 \%$} \\
\hline
\end{tabular}

node between two or more than two nodes which have more residual energy than threshold range of energy. So, extra calculation used more energy which leads to depletion of energy in DSS as compared to DARE protocol. The focusing point in tie situation is to select forwarder node, but unfortunately no one focused on it.

\section{Conclusions \& Future Work}

Many research papers have been published which focus on different types of parameters such as topology, QoS, energy consumption, network life time, end-to-end delay etc. In different research papers, researchers proposed different types of protocols to improve the performance of WBASNs by focusing on the above-mentioned parameters. In this thesis, we focused on increasing throughput, stability and decrease end-to-end delay. To achieve this goal, we presented a complete topology with mathematical equation and work. In this topology, we 
placed eight sensors on human body with two sinks. The main goal was to implement AnyCasting with two sinks and used RSSI in mathematical work to select forwarder node in tie case situation.

Through Matlab simulator we compared our DSS protocol with existing protocols DARE, SIMPLE, LAEEBA and M-ATTEMPT. The performances of DARE, SIMPLE, LAEEBA and M-ATTEMPT protocols have been analyzed before simulation. These five protocols performance has analyzed individual parameter separately in different time (seconds) started from $600 \mathrm{~s}$ to $9000 \mathrm{~s}$.

Simulation results show that DSS performance is better than DARE, SIMPLE, LAEEBA and M-ATTEMPT in Network life time, End-to-End delay and throughput. DSS performance is better because of two sinks available instead on one. Sensors send the data to S1 or S2 in AnyCasting manner. Other reason is that more of nodes lie near to sink directly. This makes the transmission of data more in less time. In this research, we also proved that the consumption of energy in DSS comes in tradeoff with above mentioned parameters. Improvement was got in all the above-mentioned parameters except energy efficiency. Hence the result proved that DSS is much better than SIMPLE, LAEEBA and M-ATTEMPT but not efficient from DARE. It is because DARE only focused on energy parameter in WBASNs. In DSS we focused on throughput, end-to-end delay and network life time parameters to improve. Another reason is that we introduced RSSI, for which the protocols make more calculation due to which more energy is consuming.

In future, we will focus on energy conservation in our proposed design and try to implement energy harvest concept. This new concept will increase the performance in great extant. In energy harvest concept sensors gain energy form external sources like solar system, wind power and thermal energy etc and used it in processing purpose. Another challenge also exists in WBASNs which are still unresolved. Some of them are data management, scalability, security and constant monitoring etc.

\section{References}

[1] Yousaf, S., Ahmed, S., Akbar, M., Javaid, N., Khan, Z. A. and Qasim, U. (2014) Incremental Relay-Based Co-Cestat Protocol for Wireless Body Area Networks. In Broadband and Wireless Computing, Communication and Applications (BWCCA), 2014 Ninth International Conference on IEEE, Guangdong, China, November 2014 113-119.

[2] Tauqir, A., Javaid, N., Akram, S., Rao, A. and Mohammad, S.N. (2013) Distance Aware Relaying Energy-Efficient: Dare to Monitor Patients in Multi-Hop Body Area Sensor Networks. In Broadband and Wireless Computing, Communication and Applications (BWCCA), 2013 Eighth International Conference on IEEE, Compiegne, France, October 2013, 206-213.

[3] Nadeem, Q., Javaid, N., Mohammad, S.N., Khan, M.Y., Sarfraz, S. and Gull, M. (2013) Simple: Stable Increased-Throughput Multi-Hop Protocol for Link Efficiency in Wireless Body Area Networks. In Broadband and Wireless Computing Communication and Applications (BWCCA), 2013 Eighth International Confe- 
rence on IEEE, Compiegne, France, October 2013, 221-226.

[4] Nadeem, A., Hussain, M.A., Owais, O., Salam, A., Iqbal, S. and Ahsan, K. (2015) Application Specific Study, Analysis and Classification of Body Area Wireless Sensor Network Applications. Computer Networks, 83, 363-380.

https://doi.org/10.1016/j.comnet.2015.03.002

[5] Akram, S., Javaid, N., Tauqir, A., Rao, A. and Mohammad, S.N. (2013) THE-FAME: Threshold Based Energy-Efficient Fatigue Measurement for Wireless Body Area Sensor Networks Using Multiple Sinks. In Broadband and Wireless Computing, Communication and Applications (BWCCA), 2013 Eighth International Conference on IEEE, Compiegne, France, October 2013, 214-220.

[6] Bahanfar, S., Darougaran, L., Kousha, H. and Babaie, S. (2011) Reliable Communication in Wireless Body Area Sensor Network for Health Monitoring. arXiv preprint arXiv: 1112.0393.

[7] Khan, Z.A., Rasheed, M.B., Javaid, N. and Robertson, B. (2014) Effect of Packet Inter-Arrival Time on the Energy Consumption of Beacon Enabled MAC Protocol for Body Area Networks. Procedia Computer Science, 32, 579-586.

https://doi.org/10.1016/j.procs.2014.05.463

[8] Ahmed, S., Javaid, N., Akbar, M., Iqbal, A., Khan, Z.A. and Qasim, U. (2014) LAEEBA: Link Aware and Energy Efficient Scheme for Body Area Networks. In Advanced Information Networking and Applications (AINA), 2014 IEEE 28th International Conference on IEEE, Victoria, BC, Canada, May 2014, 435-440.

[9] Javaid, N., Abbas, Z., Fareed, M.S., Khan, Z.A. and Alrajeh, N. (2013) M-ATTEMPT: A New Energy-Efficient Routing Protocol for Wireless Body Area Sensor Networks. Procedia Computer Science, 19, 224-231.

https://doi.org/10.1016/j.procs.2013.06.033

[10] Fazl-e-Hadi, A.A.M. (2011) EAA: Energy Aware Anycast Routing in Wireless Sensor Networks. Journal of Engineering and Applied Sciences (JEAS), 30, 1-13.

[11] Prasanna, S. and Rao, S. (2012) An Overview of Wireless Sensor Networks Applications and Security. International Journal of Soft Computing and Engineering (IJSCE), ISSN 2231-2307.

[12] Wei, W., Wang, B., Zhang, C., Towsley, D. and Kurose, J. (2004) Classification of Access Network Types: LAN, Wireless LAN, ADSL, Cable or Dialup. Proceedings of IEEE Infocom, New York, NY, USA, March 2005, 3205-3217.

[13] Gopalakrishnan, S. (2014) A Survey of Wireless Network Security. International Journal of Computer Science and Mobile Computing, 3, 53-68.

[14] Simic, D. and Prodanovic, R. (2007) A Survey of Wireless Security. CIT. Journal of Computing and Information Technology, 15, 237-255. https://doi.org/10.2498/cit.1000877

[15] Singh, R.K. and Singh, S. (2012). Architecture of Wireless Network. International Journal of Computer Science Issues (IJCSI), 9, 489-492.

[16] Dinkar, P., Gulavani, A., Ketkale, S., Kadam, P. and Dabhade, S. (2013) Remote Health Monitoring using Wireless Body Area Network. International Journal of Engineering and Advanced Technology, 2249, 8958.

[17] Kumari, J. and Prachi (2015) An Energy Efficient Routing Algorithm for Wireless Body Area Network. IJWMT, 5, 56-62. https://doi.org/10.5815/ijwmt.2015.06

[18] Kaur, H.P. and Goyal, K. (2015) Cost Based Efficient Routing for Wireless Body Area Networks.

[19] Liu, S., Wei, X. and Zhao, M. (2016) Routing Design and Simulation of Body Area 
Network Based on Node Energy Consumption Control Strategy.

[20] Arrobo, G.E. and Gitlin, R.D. (2011) Improving the Reliability of Wireless Body Area Networks. In: Engineering in Medicine and Biology Society, Annual International Conference of the IEEE, 2192-2195.

https://doi.org/10.1109/IEMBS.2011.6090413

[21] D'Andreagiovanni, F. and Nardin, A. (2015) Towards the Fast and Robust Optimal Design of Wireless Body Area Networks. Applied Soft Computing, 37, 971-982. https://doi.org/10.1016/j.asoc.2015.04.037

[22] Zhou, Y., Sheng, Z., Mahapatra, C., Leung, V.C. and Servati, P. (2017) Topology Design and Cross-Layer Optimization for Wireless Body Sensor Networks. Ad Hoc Networks. https://doi.org/10.1007/978-3-319-51204-4

[23] Hassan, M.M., Lin, K., Yue, X. and Wan (2017) A Multimedia Healthcare Data Sharing Approach through Cloud-Based Body Area Network. Future Generation Computer Systems, 66, 48-58. https://doi.org/10.1016/j.future.2015.12.016

[24] Ahmed, S., Javaid, N., Yousaf, S., Ahmad, A., Sandhu, M.M., Imran, M., Alrajeh, N., et al. (2015) Co-LAEEBA: Cooperative Link Aware and Energy Efficient Protocol for Wireless Body Area Networks. Computers in Human Behavior.

https://doi.org/10.1016/j.chb.2014.12.051

[25] Javaid, N., Faisal, S., Khan, Z.A., Nayab, D. and Zahid, M. (2013) Measuring Fatigue of Soldiers in Wireless Body Area Sensor Networks. In: 8th International Conference on Broadband and Wireless Computing, Communication and Applications, 227-231.

[26] Xu, J., Liu, W., Lang, F., Zhang, Y. and Wang, C. (2010) Distance Measurement Model Based on RSSI in WSN. Wireless Sensor Network, 2, 606.

https://doi.org/10.4236/wsn.2010.28072 